\title{
Значение экспрессии коллагена IV типа, Кі-67 и MMP-9 в мышечно-неинвазивном уротелиальном раке мочевого пузыря для прогноза течения заболевания
}

Харьковская медициская академия последипломного образования

Получено 14.02.2019

Принято в печать 04.04.2019

DOI: 10.32471/clinicaloncology.2663-466X.38.22293

\begin{abstract}
Рак мочевого пузыря (РМП) в 70-80\% случаев диагностируют на мышечно-неинвазивной стадии, при этом рецидивы возникают у порядка 70\% пациентов. В рутинной диагностике неинвазивного уротелиального рака мочевого пузыря (НУРМП) (стадии Т1) иммуногистохимическое исследование может дать объективную оценку биологическому поведению опухоли, а также служить критерием прогноза течения заболевания. Цель исследования - изучение экспрессии маркеров Кi-67, матриксной металлопротеиназы-9 (matrix metalloproteinase-9 - MMP-9) и коллагена IV типа в НУРМП для выявления критериев прогноза рецидивирования и прогрессии заболевания. Объект и методы. Сформированы две группы исследования: НУРМп без рецидивирования - I группа (14 случаев), первичные НУРМП с рецидивированием без прогрессии - II группа (14 случаев) и первичные НУРМП с рецидивированием и прогрессией во вторичной опухоли в виде инвазии в мышечный слой стенки III группа (14 случаев). Иммуногистохимическое исследование проводилось с использованием первичных моноклональных антител фирмы DAKO к коллагену IV типа, MMP-9 и Ki-67. Показатели экспрессии маркеров, связанных с иммунным ответом, изучали в трех полях зрения микроскопа на гистологических срезах с наиболее выраженной экспрессией при увеличении $\times 400$. Подсчет количества экспрессирующих маркеры клеток проводился на микроскопе Primo Star с фотокамерой при увеличении объектива $\times 400$ раз с помощью программы Adobe Photoshop CS6. Площадь тестирования составила 0,057 мм² (57 000 мкм²). Для оценки иммуногистохимической реакции использовали полуколичественную шкалу от 0 до 3 с учетом процента экспрессирующих маркер клеток в поле зрения. Реакция на Кі-67: 1 балл - до 20\% опухолевых клеток в поле зрения, 2 балла 20-50\% опухолевых клеток, 3 балла - более $50 \%$ опухолевых клеток. Реакция на коллаген IV типа: 0 - отсутствие реакции или экспрессия в менее 5\% площади опухоли, 1 балл - слабая, прерывистая экспрессия маркера, 2 балла - непрерывное четкое окрашивание базальных мембран. Реакция на МMP-9: 1 балл - до 50\% опухолевых клеток, 2 балла - более 50\% опухолевых клеток различной степени интенсивности, 3 балла - интенсивная экспрессия 100\% опухолевых клеток. Результаты и их обсуждение. Для НУРМП высокой степени злокачественности характерна экспрессия Кі-67 более $20 \%$ опухолевых клеток $(p<0,0001)$, выраженная экспрессия MMP-9 $(p<0,05)$ и отсутствие реакции на коллаген IV типа $(p<0,01)$, что определяет эти маркеры как критерии злокачественности НУРМП. В I группе НУРМП экспрессия Кі-67 и ММР-9 ниже, чем в III ( $<<0,01$ и p <0,03 соответственно). Слабая экспрессия MMP-9 и Ki-67 (до 20\% опухолевых клеток) характерна для I группы ( $p<0,03$ и p<0,005 соответственно), выраженная экспрессия Кі-67 (более 50\% опухолевых клеток) - для III группы ( $<<0,03$ ). Прослежена прямая корреляционная зависимость между экспрессией Кi-67 и MMP-9 $(p<0,01)$ и обратная зависимость между экспрессией Ki-67 и коллагена IV типа $(p<0,01)$, MMP-9 и коллагена IV типа, что характеризует взаимосвязь процессов повышения пролиферативной активности раковых клеток с возрастанием их способности к продуцированию металлопротеиназ и разрушению экстрацеллюлярного матрикса, и коллагена IV типа в частности. Эти изменения приводят к более агрессивному биологическому поведению опухоли и могут служить критериями прогноза заболевания.
\end{abstract}

Ключевые слова: неинвазивный уротелиальный рак мочевого пузыря; иммуногистохимия; Кі-67; MMP-9; коллаген IV типа; рецидив; прогрессия.

Рак мочевого пузыря (РМП) является наиболее частым злокачественным новообразованием мочевыводящих путей [1, 2]. В 70-80\% случаев РМП диагностируют на мышечно-неинвазивной стадии, при этом рецидивы возникают у порядка 70\% пациентов [3]. Для прогноза рецидивирования и прогрессии неинвазивного уротелиального РМП (НУРМП) (стадии Т1) одним из основных критериев является дифференцировка опухоли. Однако этот критерий не всегда отображает характер клинического поведения опухоли и относится к субъективным признакам, то есть зависит от интерпретации данных патоморфологом. Иммуногистохимическое исследование может служить более надежным методом прогноза заболевания. Среди онкомаркеров, используемых для диагностики РМП, представляют интерес индекс пролиферации Кi-67, определяющий активность опухолевого роста, матриксная металлопротеиназа-9 (matrix metalloproteinase-9 - ММР-9), свидетельствующая об инвазивном потенциале опухоли, ее способности разрушать компоненты экстрацеллюлярного матрикса, в том числе базальную мембрану [4, 5], и коллаген IV типа, в норме являющийся компонентом базальных мем- бран, потеря экспрессии которого связана с характером роста, инвазией, утратой способности опухоли к формированию дифференцированных структур [6].

Целью исследования явилось изучение экспрессии иммуногистохимических маркеров Кi-67, ММР-9 и коллагена IV типа в НУРМП с целью выявления критериев прогноза рецидивирования и прогрессии заболевания.

\section{ОБЪЕКТ И МЕТОДЫ ИССЛЕДОВАНИЯ}

Материалом исследования явились оперативно удаленные в Харьковском областном клиническом центре урологии и нефрологии имени В.И. Шаповала 42 уротелиальных новообразования мочевого пузыря стадии Т1, то есть без инвазии в мышечный слой стенки органа.

Сформированы три группы исследования: НУРМП без рецидивирования - I группа (14 случаев), НУРМП с рецидивированием без прогрессии - II группа (14 случаев) и НУРМП с рецидивированием и прогрессией в виде инвазии в мышечный слой стенки - III группа (14 случаев). В каждую из групп было включено равное число опухолей низкой степе- 
ни злокачественности (НС3) - по 8 случаев и высокой степени злокачественности (ВС3) - по 6 случаев.

Иммуногистохимическое исследование проводилось с использованием первичных моноклональных антител фирмы DAKO (Дания), Rady-to-Use к коллагену IV типа, MMP-9 и Ki-67. Показатели экспрессии маркеров, связанных с иммунным ответом, изучали в трех полях зрения микроскопа на гистологических срезах с наиболее выраженной экспрессией при увеличении $\times 400$. Подсчет количества экспрессирующих маркеры клеток проводился на микроскопе Primo Star c фотокамерой при увеличении объектива $\times 400$ с помощью программы Adobe Photoshop CS6. Площадь тестирования составила 0,057 мм² $^{2}$

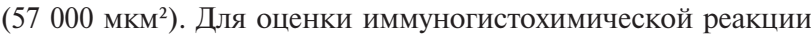
использовали полуколичественную шкалу от 0 до 3 с учетом процента экспрессирующих маркер клеток в поле зрения. Реакция на Ki-67: 1 балл - до 20\% опухолевых клеток в поле зрения, 2 балла - 20-50\% опухолевых клеток, 3 балла - более $50 \%$ опухолевых клеток. Реакция на коллаген IV типа: $0-$ отсутствие реакции или экспрессия в менее 5\% площади опухоли, 1 балл - слабая, прерывистая экспрессия маркера, 2 балла - непрерывное четкое окрашивание базальных мембран. Реакция на ММР-9: 1 балл до $50 \%$ опухолевых клеток, 2 балла - более $50 \%$ опухолевых клеток различной степени интенсивности, 3 балла - интенсивная экспрессия $100 \%$ опухолевых клеток. Статистическую обработку результатов исследования проводили с использованием пакета Statistica 6.0. Связь между признаками оценивалась по непараметрическому критерию $\chi^{2}$ Пирсона и критерию Спирмана. Статистически значимым считалось значение $\mathrm{p}<0,05$.

\section{РЕЗУЛЬТАТЫ И ИХ ОБСУЖДЕНИЕ}

Исследованные случаи НУРМП были представлены опухолями с различной гистоархитектоникой, дифференцировкой, особенностями инвазии. Как правило, новообразования имели папиллярную структуру с экзофитным ростом, сохраненной базальной мембраной, демонстрирующей хорошо выраженную экспрессию коллагена IV типа на границе со стромой. Такого рода папиллярные гистоструктуры, часто сливного характера, присутствовали в НУРМП НСЗ. Выраженные изменения гистоархитектоники сопровождались уменьшением площади стромального компонента, участками солидного строения, зонами инвазии в подслизистую основу (lamina propria) и гетерогенной реакцией коллагена IV типа, исчезновение которой чаще было характерно для зон пальцевидной инвазии, но наблюдалось и при фронтальном росте опухоли. Реакция на коллаген IV типа зависела от дифференцировки НУРМП. Так, 42,9\% (18/42) опухолей характеризовались отсутствием экспрессии коллагена IV типа в участках инвазии, при этом в НУРМП ВСЗ отсутствие коллагена IV типа было в 77,8\% (14/18), а в НУРМП НС3 в $41,7 \%(10 / 24)$ случаев $\left(\mathrm{c}^{2}=5,47, \mathrm{p}<0,01\right)$.

Анализ экспрессии коллагена IV в группах исследования показал, что во II и III группах по сравнению с I отмечалось увеличение количества случаев с отрицательной экспрессией маркера, однако достоверных различий не выявлено (таблица).

Таблица. Распределение экспрессии коллагена IV типа, MMP-9, Кі-67 в НУРМП в зависимости от их принадлежности к группам исследования

\begin{tabular}{|c|c|c|c|c|c|}
\hline \multirow{2}{*}{\multicolumn{2}{|c|}{$\begin{array}{l}\text { Маркер, } \\
\text { экспрессия }\end{array}$}} & \multicolumn{3}{|c|}{ Группы } & \multirow{3}{*}{$\begin{array}{c}\text { Достовер- } \\
\text { ность, крите } \\
\text { рий } \chi^{2} \\
\chi^{2}=2,33\end{array}$} \\
\hline & & \multirow{2}{*}{$\begin{array}{c}\text { I, } \mathbf{n}(\%) \\
\mathbf{n}=14\end{array}$} & \multirow{2}{*}{$\begin{array}{c}\text { II, n (\%) } \\
\mathbf{n}=\mathbf{1 4} \\
8(57,1)\end{array}$} & \multirow{2}{*}{$\begin{array}{c}\begin{array}{c}\text { III, } \mathbf{n}(\%) \\
\mathbf{n}=\mathbf{1 4}\end{array} \\
10(71,4)\end{array}$} & \\
\hline Коллаген & 0 & & & & \\
\hline \multirow[t]{2}{*}{ IV типа } & $1+$ & $8(57,1)$ & $6(42,9)$ & $4(28,6)$ & $\mathrm{p}=0,31$ \\
\hline & $2+$ & 0 & 0 & 0 & $\left(x^{2}\right.$ crit $\left.=5,99\right)$ \\
\hline \multirow[t]{4}{*}{ Ki-67 } & 0 & 0 & 0 & 0 & $x^{2}=10,31$ \\
\hline & $1+$ & $10(71,4)$ & $5(35,7)$ & $2(14,3)$ & $p=0,03$ \\
\hline & $2+$ & $4(28,6)$ & $8(57,1)$ & $10(71,4)$ & $\left(X^{2}\right.$ crit $\left.=9,48\right)$ \\
\hline & $3+$ & 0 & $1(7,2)$ & $2(14,3)$ & \\
\hline \multirow[t]{4}{*}{ MMP-9 } & 0 & 0 & 0 & 0 & $x^{2}=7,5$ \\
\hline & $1+$ & $8(57,1)$ & $4(28,6)$ & $2(14,3)$ & $p=0,11$ \\
\hline & $2+$ & $4(28,6)$ & $4(28,6)$ & $4(28,6)$ & $\left(X^{2}\right.$ crit $\left.=9,48\right)$ \\
\hline & $3+$ & $2(14,3)$ & $6(42,8)$ & $8(57,1)$ & \\
\hline
\end{tabular}

НУРМП характеризовался различной пролиферативной активностью опухолевых клеток. Уровень экспрессии Ki-67 в среднем составил $30,71 \pm 5,11 \%$ и зависел от дифференцировки опухоли. Так, все случаи рака с пролиферативной активностью 3+ были среди НУРМП ВС3, а низкая пролиферативная активность $(1+)$ была характерна для НУРМП НС3 $\left(\chi^{2}=15,9 ; \mathrm{p}<0,0001\right)$. Различия между НУРМП НС3 и НУРМП ВС3 по уровню экспрессии Кi-67 достоверны $\left(\chi^{2}=17,36\right.$; $\mathrm{p}<0,0001)$. Полученные результаты согласуются с данными научной литературы [7] и являются закономерными, поскольку дифференцировка НУРМП определяется уровнем митотической активности, а следовательно, зависит и от процента клеток, экспрессирующих Кі-67. По данным некоторых авторов, маркер пролиферативной активности Кi-67 является критерием прогноза прогрессии заболевания и выживаемости пациентов [8], однако сведения противоречивы [9].

Выявлена слабая зависимость между уровнем экспрессии Ki-67 и принадлежности опухоли к группам исследования $\left(\chi^{2}=10,31 ; \mathrm{p}<0,03\right)$. Экспрессия Ki-67 1+ была характерна для НУРМП I группы $\left(\chi^{2}=8,3 ; \mathrm{p}<0,005\right)$, не характерна для III группы $\left(\chi^{2}=5,9 ; p<0,03\right)$, выраженная экспрессия $(3+)$ была присуща III группе $\left(\chi^{2}=5,8 ; p<0,03\right)$. Однако зависимость между изученным маркером и принадлежностью опухоли к группам исследования была слабой $(p=0,03)$ за счет достоверно значимого различия между I и III группами $\left(\chi^{2}=9,9\right.$; $\mathrm{p}=0,007)$, в то время как достоверно значимого различия между I и II группами не наблюдалось $\left(\chi^{2}=4 ; p=0,13\right)$. Полученные данные в целом указывают на ограниченное значение этого маркера для прогноза рецидивирования и прогрессии.

Прослежена обратная корреляционная связь между уровнем экспрессии Ki-67 и коллагена IV ( $\mathrm{r}=-0,755$; $\mathrm{p}<0,01)$. Так, в НУРМП со слабой экспрессией Кі-67 экспрессия коллагена IV типа была хорошо выражена, а по мере возрастания экспрессии Кi-67 в опухолях, демонстрирующих возрастание инвазивных свойств и снижение дифференцировки, экспрессия коллагена IV типа снижалась.

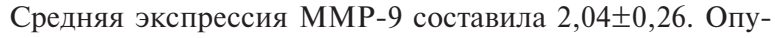
холевые клетки, которые более интенсивно окрашивались маркером, отличались более выраженной клеточной атипией. Прослежена зависимость уровня экспрессии ММР-9 и дифференцировки НУРМП $\left(\chi^{2}=11,86 ;\right.$ p=0,002). Выраженный уровень экспрессии был характерен для НУРМП ВС3 $\left(\chi^{2}=4,0 ; p<0,05\right)$ и отмечался в 55,6\% (10/18) случаев этой дифференцировки. Образцы нерецидивирующего НУРМП (І группы) характеризовались наиболее слабой реакцией на ММР-9 при сравнении с опухолями, давшими рецидивы с прогрессией (III группой), различия достоверны $\left(\chi^{2}=7,2 ; p<0,03\right)$. Слабый уровень экспрессии ММР-9 (1+) был характерен для I группы $\left(\chi^{2}=5,3 ; \mathrm{p}<0,03\right)$. В целом полученные результаты согласуются с данными других авторов. Высокая экспрессия ММР является критерием прогноза рецидивирования, низкой общей выживаемости пациентов и выживаемости, связанной с прогрессией рака [10, 11].

Прослежена прямая корреляционная связь между уровнем экспрессии ММР-9 и Кi-67 (r=0,783; $\mathrm{p}<0,01)$. Таким образом, обнаружена прямая зависимость между возрастанием способности раковых клеток к продуцированию металлопротеиназ, разрушающих компоненты экстрацеллюлярного матрикса, и повышением пролиферативной активности опухоли, что обусловливает активный рост и распространение рака. Выявлена также обратная корреляционная зависимость между MMP-9 и коллагеном IV типа ( $\mathrm{r}=-0,863, \mathrm{p}<0,01)$, что согласуется со способностью MMP-9 разрушать коллаген IV типа и в целом указывает на взаимосвязь исследованных нами трех маркеров в процессах опухолевой прогрессии.

\section{выводы}

1. Для НУРМП ВС3 характерна экспрессия Ki-67 более $20 \%$ опухолевых клеток ( $<0,0001)$, выраженная экспрессия MMP-9 $(\mathrm{p}<0,05)$ и отсутствие реакции на коллаген IV типа 
$(\mathrm{p}<0,01)$, что определяет эти маркеры как критерии злокачественности НУРМП.

2. В образцах нерецидивирующего НУРМП экспрессия Ki-67 и ММР-9 ниже, чем в опухолях рецидивирующего с прогрессией НУРМП ( $<<0,01$ и p $<0,03$ соответственно). Слабая экспрессия ММР-9 и Кі-67 (до 20\% опухолевых клеток) характерна для нерецидивирующего НУРМП ( $<0,03$ и $\mathrm{p}<0,005$ соответственно), выраженная экспрессия Кі-67 (более 50\% опухолевых клеток) - для рецидивирующего с прогрессией НУРМП ( $<<0,03)$.

3. Прослежена прямая корреляционная зависимость между экспрессией Ki-67 и ММР-9 $(\mathrm{p}<0,01)$ и обратная зависимость между экспрессией Ki-67 и коллагена IV типа $(\mathrm{p}<0,01)$, MMP-9 и коллагена IV типа, что характеризует взаимосвязь процессов повышения пролиферативной активности раковых клеток с возрастанием их способности к продуцированию металлопротеиназ и разрушению экстрацеллюлярного матрикса, и коллагена IV типа в частности. Эти изменения приводят к более агрессивному биологическому поведению опухоли и могут служить критериями прогноза заболевания.

\section{СПИСОК ИСПОЛЬЗОВАННОЙ ЛИТЕРАТУРЫ}

1. Nagata M., Muto S., Horie S. (2016) Molecular biomarkers in bladder cancer: novel potential indicators of prognosis and treatment outcomes. Dis. Markers. 2016: 8205836. doi: $10.1155 / 2016 / 8205836$

2. Gschwend J.E., Dahm P., Fair W.R. (2002) Disease specific survival as endpoint of outcome for bladder cancer patients following radical cystectomy. Eur. Urol., 41: 440-448. doi: 10.1016/S0302-2838(02)00060-X

3. Ogata D.C., Marcondes C.A., Tuon F.F. et al. (2012) Superficial papillary urothelial neoplasms of the bladder (PTA E PT 1): Correlation of expression of P53, Ki-67 and CK 20 with histologic grade, recurrence and tumor progression. Rev. Col. Bras. Cir., 39: 394-400. doi: 10.1590/S0100-69912012000500010

4. Enache M., Simionescu C., Lascu L.C. (2012) Ki67 and Bcl-2 immunoexpression in primitive urothelial bladder carcinoma. Rom. J. Morphol. Embryol., 53(3): 521-525. PMID: 22990542

5. Mannello F., Tonti G., Papa S. (2005) Matrix metalloproteinase inhibitors as targets of anticancer therapeutics. Curr. Cancer Drug Targets., 5: 285-298. DOI: $10.2174 / 1568009054064615$

6. Brunner A., Tzankov A. (2007) The role of structural extracellular matrix proteins in urothelial bladder cancer (review). Biomarker Insights., 2: 418. PMID: 19662222 PMCID: PMC2717820

7. Ahn C., Jeong C.W., Kwak C. et al. (2018) Ki-67 as a prognostic marker in upper urinary tract urothelial carcinoma: a systematic review and meta-analysis. Clin. Genitourin. Cancer, 16(4): 1-9. doi: 10.1016/j.clgc.2018.02.010

8. Wu P., Liu S., Zhang W. et al. (2015) Low-level Ki-67 expression as an independent predictor of bladder tumour recurrence in patients with primary upper tract urothelia carcinoma after radical nephroureterectomy. Jpn J. Clin. Oncol., 45(12): 1175-1181. doi: 10.1093/jjco/hyv139

9. Yalçin Ö., Sağlican Y., Özdemir S. et al. (2015) The relationship of p16, Ki-67, $\mathrm{BCl}-2, \mathrm{P} 53$ and CK20 immune expressions with recurrence in superficial bladder tumors. World J. Pathol., 8: 44-51. http://www.npplweb.com/wjp/content/4/8

10. Wu G.J., Bao J.S., Zeng F.C. et al. (2018) Elevated expression of matrix metalloproteinase- 9 is associated with bladder cancer pathogenesis. J. Cancer Res. Ther., 14(Suppl.): S54-S59. doi: 10.4103/0973-1482.163761

11. Chenkui M., Chao L., Jundong Z. et al. (2017) Prognostic role of matrix metaloproteinases in bladder carcinoma: a systematic review and meta-analysis. Oncotarget, 8(19): 32309-32321. doi: 10.18632/oncotarget. 15907

\section{Значення експресії колагену IV типу, \\ Ki-67 і MMP-9 у м'язово-неінвазивному \\ уротеліальному раку сечового міхура \\ для прогнозу перебігу захворювання}

\section{I.I. Яковиова, С.В. Титов, І.В. Івахно, О.В. Долгая, С.В. Данилюк} Харківська медична академія післядипломної освіти

Резюме. Рак сечового міхура (РСМ) в 70-80\% випадків діагностують на м'язово-неінвазивній стадії, при цьому рецидиви виникають у майже $70 \%$ пацієнтів. У рутинній діагностиці неінвазивного уротеліального раку сечового міхура (НУРСМ) (стадії Т1) імуногістохімічне дослідження може дати об’єктивну оцінку біологічної поведінки пухлини, а також служити критеріями прогнозу перебігу захворювання. Mema дослідження вивчення експресії маркерів Кі-67, матриксної металопротеїнази-9 (matrix metalloproteinase-9 - MMP-9) і колагену IV типу в НУРСМ для виявлення критеріїв прогнозу рецидивування і прогресії захворювання. Об’єкт і методи дослідження. Сформовані дві групи дослідження: НУРСМ без рецидивування I група (14 випадків), первинні НУРСМ з рецидивуванням без прогресії - II група (14 випадків) та первинні НУРСМ з рецидивуванням і прогресією у вторинні пухлини у вигляді інвазії в м’язовий шар стінки - III група (14 випадків). Імуногістохімічне дослідження проводилося з використанням первинних моно- клональних антитіл фірми DAKO до колагену IV типу, MMP9 і Ki-67. Показники експресії маркерів, пов'язаних з імунною відповіддю, вивчали в трьох полях зору мікроскопа на гістологічних зрізах із найбільш вираженою експресією при збільшенні ×400. Підрахунок кількості експресуючих маркери клітин проводився на мікроскопі Primo Star з фотокамерою при збільшенні об'єктива 400 за допомогою програми Adobe Photoshop CS6. Площа тестування становила 0,057 мм² (57 000 мкм²). Для оцінки імуногістохімічної реакції використовували напівкількісну шкалу від 0 до 3 з урахуванням відсотка експресуючих маркер клітин в полі зору. Реакція на Кі-67: 1 бал - до 20\% пухлинних клітин у полі зору, 2 бали - 20-50\% пухлинних клітин, 3 бали - більше $50 \%$ пухлинних клітин. Реакція на колаген IV типу: 0 - відсутність реакції або експресія в менше ніж 5\% площі пухлини, 1 бал - слабка, переривчаста експресія маркера, 2 бали - безперервне чітке фарбування базальних мембран. Реакція на ММР-9: 1 бал - до 50\% пухлинних клітин, 2 бали більше 50\% пухлинних клітин різного ступеня інтенсивності, 3 бали - інтенсивна експресія 100\% пухлинних клітин. Результати та їх обговорення. Для НУРСМ високого ступеня злоякісності характерна експресія Кі-67 більше $20 \%$ пухлинних клітин ( $<<0,0001)$, виражена експресія ММР-9 (p<0,05) і відсутність реакції на колаген IV типу $(\mathrm{p}<0,01)$, що визначає ці маркери як критерії злоякісності НУРСМ. У І групі НУРСМ експресія Ki-67 і ММР-9 нижче, ніж в III ( $<<0,01$ і р<0,03 відповідно). Слабка експресія ММР-9 і Кі-67 (до 20\% пухлинних клітин) характерна для I групи ( $<<0,03$ і p <0,005 відповідно), виражена експресія Кі-67 (більше 50\% пухлинних клітин) - для III групи $(\mathrm{p}<0,03)$. Простежена пряма кореляційна залежність між експресією Ki-67 і MМР-9 (p<0,01) і зворотна залежність між експресією Кi-67 і колагену IV типу (p<0,01), MМР-9 і колагену IV типу, що характеризує взаємозв'язок процесів підвищення проліферативної активності ракових клітин зі зростанням їхньої здатності до продукування металопротеїназ і руйнування екстрацелюлярного матриксу, та колагену IV типу зокрема. Ці зміни призводять до більш агресивної біологічної поведінки пухлини і можуть служити критеріями прогнозу захворювання.

Ключові слова: неінвазивний уротеліальний рак сечового міхура; імуногістохімія; Кі-67; MMP-9; колаген IV типу; рецидив; прогресія.

The significance of collagen IV type,

Ki-67 and MMP-9 expression in non-invasive urothelial cancer of bladder for prediction of the disease

\section{I.I. Yakovtsova, E.V. Titov, I.V. Ivakhno, O.V. Dolgaya, S.V. Daniluk} Kharkiv Medical Academy of Postgraduate Education

Summary. Bladder cancer (BC) in $70-80 \%$ of cases are diagnosed as non-muscle-invasive (stage $\mathrm{T} 1$ ), the overall rate of recurrence for non-muscle-invasive bladder cancer (NMIBC) is approximately $70 \%$. Immunohistochemistry represents an important objective complementary tool for the routine diagnosis of NMIBC and for the indentification of the tumor biological behavior and also serve as criteria for predicting recurrence and progression of the disease. The aim of present stady is to investigate the expression of Ki-67, matrix metalloproteinase-9 (MMP-9) and collagen IV type in NMIBC for identifation the criteria for recurrence and progression of the disease. Materials and methods. Three groups of research were formed: NMIBC without recurrence - group I (14 cases), the primary NMIBC with recurrence without progression - group II (14 cases) and the primary NMIBC with recurrence and progression in secondary tumors in the form of invasion in muscle layer - group III (14 cases). An immunohistochemical study was carried out using primary monoclonal antibodies of DAKO to type IV collagen, MMP-9 and Ki-67. The expression indicators of markers associated with the immune response were studied in three fields of view of the microscope of histological sections with the most pronounced expression at magnification $\times 400$. Counting the number of cells expressing markers was carried out on a Primo Star microscope with a camera with an increase in $\times 400$ lens using Adobe Photoshop CS6. The area of testing was $0.057 \mathrm{~mm}^{2}\left(57,000 \mu \mathrm{m}^{2}\right)$. Reaction to $\mathrm{Ki}-67: 1$ point - 
up to $20 \%$ of tumor cells in sight, 2 points $-20-50 \%$ of tumor cells, 3 points - more than $50 \%$ of tumor cells. Reaction to type IV collagen: $0-$ no reaction or expression in less than $5 \%$ of the tumor area, 1 point weak, intermittent expression of the marker, 2 points - continuous clear staining of the basement membranes. Reaction to MMP-9: 1 point up to $50 \%$ of tumor cells, 2 points - more than $50 \%$ of tumor cells of varying degrees of intensity, 3 points - intense expression of $100 \%$ of tumor cells. Results and discussion. A high grade of malignancy is characterized by expression of Ki-67 over $20 \%$ of tumor cells ( $p<0.0001)$, pronounced expression of MMP-9 $(\mathrm{p}<0.05)$ and lack of response to type IV collagen $(p<0.01)$, which defines these markers as criteria for the malignancy of NMIBC. In group I expression of Ki-67 and MMP-9 is lower than in group III ( $\mathrm{p}<0.01$ and $\mathrm{p}<0.03$, respectively). Weak expression of MMP-9 and Ki-67 (up to $20 \%$ of tumor cells) are characteristics of cancers of group I ( $\mathrm{p}<0.03$ and $\mathrm{p}<0.005$, respectively), $\mathrm{Ki}-67$ expression over $50 \%$ of tumor cells associated with group III $(\mathrm{p}<0.03)$. A direct correlation between the expression of Ki-67 and MMP-9 $(p<0.01)$ and the inverse relationship between Ki-67 and type
IV collagen ( $p<0.01)$, MMP-9 and type IV collagen are traced, which characterizes the relationship processes of increasing the proliferative activity of cancer cells with an increase in their ability to produce metalloproteinases and destroy the extracellular matrix, and type IV collagen in particular. These changes lead to a more aggressive biological behavior of the tumor and can serve as criteria for the prognosis of the disease.

Key words: non-invasive urothelial cancer of the bladder; immunohistochemistry; collagen IV type; Ki-67; MMP-9; recurrence; progression.

\section{Aдрес:}

Титов Евгений Вячеславович

61000, Харьков, ул. Амосова, 58

Харьковская медииинская академия последипломного образования

E-mail: titovevgeniy@ukr.net E-mail: titovevgeniy@ukr.net 